\title{
Kannan contractions and strongly demicontractive mappings
}

\author{
ŞTEFAn MĂRUŞTER and IOAN A. RUS
}

\section{ABSTRACT.}

Inclusion relations between strongly demicontractive mappings, quasi $(L, m)$-contractions, and Kannan contractions are established. As corollaries, $T$-stability and strong convergence of Picard and Mann iterations for strongly demicontractive mappings are obtained.

\section{REFERENCES}

[1] Akuchu, B. G., Strong convergence of the Mann sequence for demicontractive maps in Hilbert spaces, Adv. Fixed Point Theory, 4 (2014), No. 3 , 415-419

[2] Berinde, V., Approximating fixed points of weak contractions using the Picard iterations, Nonlinear Analysis Forum, 9 (2004), No. $143-53$

[3] Boonchari, D. and Saejung, S., Construction of common fixed points of a countable family of $\lambda$-demicontractive mappings in arbitrary Banach spaces, Appl. Math. Comput., 216 (2010) 173-178

[4] Chidume, C. E., Abbas, M. and Ali, B., Convergence of the Mann iteration algorithm for a class of pseudocontractive mappings, Appl. Math. Comput., 194 (2007), No. 1, 1-6

[5] Chidume, C. E. and Maruster, S., Iterative methods for the computation of fixed points of demicontractive mappings, J. Comput. Appl. Math., 234 (2010), No. 3, 861-882

[6] De la Sen, M., Some combined relations between Contractive mappings, Kannan mappings, Reasonable Expansive mappings, and T-stability, Fixed Point Theory Appl., Hindawi Publ. Corp., 2009, Art. ID 815637

[7] Hicks, T. L. and Kubicek, J. D., On the Mann iteration process in a Hilbert spaces, J. Math. Anal. Appl., 59 (1977) 489-504

[8] Kang, S. M., Rafiq, A. and Hussain, N., Weak and strong convergence of fixed points of demicontractive mappings in smooth Banach spaces, Int. J. Pure Appl. Math., 84 (2013), No. 3, 251-268

[9] Kannan, R., Some results on fixed points, Bull. Calcutta. Math. Soc., 60 (1968), 71-76

[10] Kikkawa, M. and Suzuki, T., Some similarity between contractions and Kannan mappings, Fixed Point Theory Appl., 2008, Art. ID 649749

[11] Lee, W. and Choi, Y., A survey on characterizations of metric completeness, Nonlinear Anal. Forum, 19 (2014), 265-276

[12] Maruşter, St., Sur le calcul des zeros d'un operateur discontinu par iteration, Canad. Math. Bull., 16 (1973), No. 4, 541-544

[13] Maruşter, St., The solution by iteration of nonlinear equations in Hilbert spaces, Proc. Amer. Math.Soc., 63 (1977), No. 1, 69-73

[14] Maruşter, L. and Maruşter, St., Storng convergence of the Mann iteration for $\alpha$-demiccontractive mappings, Mathematical and Computer Modeling, 54 (2011), No. (9-10), 2486-2492

[15] Ortega,J. M. and Rheinboldt, W. C., Iterative Solution of Nonlinear Equations in Several Variablea, Academic Press, New York, 1970

[16] Osilike, M. O., Stability results for fixed point iteration procedures, J. Nigerian Math. Soc., 14/15 (1995/96), 17-29

[17] Păcurar, M., Iterative methods for fixed point approximation, Ed. Risoprint, Cluj-Napoca (2009)

[18] Qing, Y. and Rhoades, B. E., T-stability of Picard iteration in metric spaces, Fixed Point Theory Appl, Hindawi Publ. Corp., 2008, Art. ID 418971

[19] Rhoades, B. E., A comparison on various definitions of contractive mappings, Trans. Amer. Math. Soc., 226 (1977) 259-290

[20] Rus, I. A., Picard operators and applications, Sc. Math. Japonicae, 58 (2003), No. 1, 191-219

[21] Rus, I. A., An abstract point of view on iterative approximation of fixed points: impact on the theory of fixed point equations, Fixed Point Theory, 13 (2012), No. 1, 179-192

[22] Shioji N., Suzuki, T. and Takahashi, W., Contractive mappings, Kannan mappings and metric completeness,. Proc. Amer. Math. Soc., 126 (1998), No. 10, 3117-3124

[23] Shioji, N., Suzuki, T. and Takahashi, W., Contractive mappings, Kannan mappings and metric completeness, Proc. Amer. Math. Soc., 126 (1998), No. $10,3117-3124$

[24] Subrahmanyam, P. V., Completenes and fixed points, Monasth. Math., 80 (1975), 325-330

[25] $\mathrm{Yu}, \mathrm{Y}$. and Sheng, D., On the strong convergence of an algorithm about Firmly Pseudo-Demicontractive mappings for the split common fixed point problem, Hindawi Publishing Corporation, J. Appl. Math. 2012, Art. ID 256930, 9 pp.

WEST UNIVERSITY OF TIMIŞOARA, ROMANIA

E-mail address: maruster@info.uvt.ro

UNIVERSITY BABES-BOLYAI

CLUJ-NAPOCA, ROMANIA

E-mail address: iarus@math.ubbcluj.ro

Received: 23.03.2015; In revised form: 29.09.2015; Accepted: 30.09.2015

2010 Mathematics Subject Classification. 47H10, 54H25, 47H09.

Key words and phrases. Fixed point, quasi contraction, quasi $(L, m)$-contraction, demicontractive mapping, Kannan contraction, Picard iteration, Mann iteration, stability. 